\title{
Social determinants of health among African-American men
}

\section{Keywords}

Social

determinants of

health

African-American men

Health disparities

Health behavior
Clare Xanthos, PhD Community Voices, Department of Community Health and Preventive Medicine, Morehouse School of Medicine, USA

Henrie M. Treadwell, $\mathrm{PhD}$

Community Voices, Department of Community Health and Preventive Medicine, Morehouse School of Medicine, USA

Kisha Braithwaite Holden, PhD Community Voices, Department of Psychiatry and Behavioral Sciences, Morehouse School of Medicine, USA

E-mail: cxanthos@msm.edu

Online 8 February 2010

\section{Clare Xanthos, Henrie M. Treadwell and Kisha Braithwaite Holden}

\begin{abstract}
The health disparities among African-American men are staggering when compared to other racial, ethnic, and gender groups in the United States. While there have been considerable efforts to eliminate health disparities in recent years, disparity elimination efforts have often focused on changing health behavior with regard to African-American men, and grave health disparities continue to exist among this population. This article argues that a consideration of the social determinants of health among AfricanAmerican men is long overdue. It highlights the serious health disparities among this population, and considers the social determinants of health of African-American men in relation to health status, health behavior, and health care. Finally, suggestions are offered for addressing the social determinants of health among African-American men. ๑ 2010 WPMH GmbH. Published by Elsevier Ireland Ltd.
\end{abstract}

\section{Introduction: the importance of social determinants of health among African-American men}

While there have been significant efforts in recent years to eliminate health disparities [1], serious disparities continue to exist especially with regard to African-American men who continue to suffer disproportionately from poor health when compared to other racial, ethnic, and gender groups in the United States (US).

Research and programs relating to AfricanAmerican men's health often focus on individual health behavior (e.g. diet, exercise, increasing doctors visits) [2]. While health behavior determines health to some extent, it is important to recognize that social and environmental factors place minorities such as African-American men at a significant disadvantage with regard to health and disease; African-American men may be exposed to numerous difficult life experiences (e.g. reduced access to quality education, reduced access to employment, disproportionate rates of incarceration) experienced less often by more advantaged groups [3]. In addition, Afri-
can-American men are among the most underserved populations in the US with regard to access to quality health services and mental health services, which similarly contributes to their poor health outcomes [4]. As such, health behavior alone does not fully explain the significant health disparities among AfricanAmerican men [2].

Accordingly, we would like to draw attention to the social determinants of health among African-American men. We also wish to highlight the necessity for research, programs, and policies that influence the social determinants of health and improve health equity among this and other disadvantaged groups. We will begin by highlighting the staggering inequalities in health among African-American men. This will be followed by a consideration of the social determinants of health affecting this population: the social determinants of health status, the social determinants of health behavior, and the social determinants of health care. Finally, we propose recommendations for tackling the social determinants of health among African-American men. These consist of suggestions for research and programs that address the social 
determinants of health among African-American men, social policies which tackle social and environmental issues affecting AfricanAmerican men's health, and health policies which promote health equity among this and other vulnerable populations.

\section{The health status of African- American men}

African-American men have the lowest life expectancy and highest mortality rate among men and women in all other racial or ethnic groups in the US. The life expectancy at birth is 70 years for Black men compared with 76 years for White men, 76 years for Black women, and 81 years for White women [5]. The mortality rate for African-American men is 1.3 times that of White men, 1.7 times that of American Indian/Alaska Native men, 1.8 times that of Hispanic men, and 2.4 times that of Asian or Pacific Islander men [6].

To cite some examples relating to chronic illnesses:

- With regard to cardiovascular disease, Black men (and women) in the US have the highest rates of hypertension in the world [7]. Additionally, in the 30-39 age group, AfricanAmerican men are about 14 times more likely to develop kidney failure due to hypertension than White men [8]. Furthermore, African-American men are $60 \%$ more likely to die from a stroke than their White adult counterparts [9]. Moreover, African-American men are $30 \%$ more likely to die from heart disease as compared with White men [10].

- With respect to cancer, Black men in the US have the highest rates of prostate cancer in the world [11]. In addition, African-American men are $37 \%$ more likely than White men to develop lung cancer [12]. Between 2000 and 2003, African-American men had an age-adjusted lung cancer death rate that was 32\% higher than that for White men (death rates of 97.2 versus 73.4 per 100,000, respectively) [12]. Also, oral (mouth) cancer is more common in African-American men than in any other group in the US [13]. The difference in survival rates for oral cancer are extremely high; while $61 \%$ of White men survive 5 years or more, only $36 \%$ of
African-American men survive 5 years or more [14].

- The mortality rate for diabetes for AfricanAmerican men is 51.7 per 100,000 as compared to 25.6 per 100,000 for their White male counterparts [10].

- African-American men are similarly disproportionately affected by the HIV/AIDs pandemic when compared to other population groups. African-American men have more than 7 times the AIDS rate of non-Hispanic White men. In addition, African-American men are more than 9 times as likely to die from HIV/AIDS as White men [10].

- The homicide death rate for young AfricanAmerican men is 84.6 per 100,000 of the population compared with 5 per 100,000 of the population for young White men [15]. To put it another way, young Black men aged 15-19 die from homicide at 46 times the rate of their White counterparts [16]. While homicide death rates decline for older AfricanAmerican men, the rates among AfricanAmerican men aged 25-44 are still disturbingly high (61 per 100,000 of the population) when compared with Whites of that age group (5.1 per 100,000 of the population) [15].

\section{Social determinants of health status}

African-American men are exposed to a multitude of social and environmental conditions that have the potential to affect their health status including both physical and mental health $[17,18]$. For the purpose of this review, the focus will be on three key social determinants of health which are particularly relevant to African-American men: low socioeconomic status, racial discrimination, and incarceration. These should not be seen as discrete factors; there is significant interplay between them as is apparent in the following discussion. While no list can be exhaustive, these three social determinants encompass a broad array of some of the most significant stressors and negative life events affecting AfricanAmerican men's health.

\section{Low socioeconomic status}

African-American men are disproportionately impacted by low socioeconomic status (SES). First, nearly 25\% of African Americans live below the poverty line, 3 times the percentage 
of Whites [16]. With regard to annual median income, African-American men earn less than $75 \%$ of what White men earn $(\$ 34,443$ compared with $\$ 46,807)$. With respect to occupation, $9.5 \%$ of African-American men are unemployed compared to $4 \%$ of White men. Additionally, African-American men are disproportionately represented in lower-income jobs [16]. Furthermore, due to disproportionately lower incomes when compared with other Americans, African-American men are often located in urban economically disadvantaged areas, with poor neighborhood conditions (e.g. substandard housing, crime, crowding, noise pollution) [19], and environmental hazards [20].

Concurrently, the relationship between low SES and poor health is well documented $[21,22]$. It has been suggested that the conditions associated with low SES lead to stress, and that stress is a pathway linking low SES to poor health outcomes [22]. As such it is clear that reduced access to socioeconomic opportunities among African-American men is an important social determinant of health. At the same time, the relationship between SES and race is complex. For example, while socioeconomic status is an important factor in explaining racial disparities in health, racial differences persist even at similar levels of SES [23]. In addition, racial discrimination can adversely affect health by restricting socioeconomic opportunities [23]. The following subsection seeks to shed some light on this issue.

\section{Racial discrimination}

Racial discrimination is a significant aspect of life for African-American men; they must deal with everyday racism (e.g. proactive police surveillance, workplace tensions) as well as institutional racism (e.g. employment discrimination). In the interests of brevity we will highlight three important discrimination-related issues faced by African-American men and boys: reduced access to quality education, reduced access to employment, and disproportionate rates of incarceration.

First, African-American male students suffer significant disparities in quality of education when compared to their White counterparts [24]. For example, underfunding of schools in African-American communities is a serious problem. In 2007, dollars spent per Black stu- dent in the US was only $82 \%$ of what was spent per White student [16]. On average, Black boys are more likely to attend the most segregated and poorest public schools than other racial, ethnic, and gender groups in the US [24]. In addition, it has been argued that school policies and practices play a role in the disproportionate levels of expulsion, suspension and special education placement among African-American boys $[25,26]$. As such there is a resulting achievement gap between Black males and other racial, ethnic, and gender groups which is well documented [24,27,28].

Second, there are significant employment disparities among African-American men and their White counterparts. African-American men are more than twice as likely to be unemployed as White men [16]. One study in 2003 [29], demonstrated that African-American men were less than half as likely to receive consideration by employers, relative to their White male counterparts. Among African-American men without criminal records, only $14 \%$ received callbacks, when compared to $34 \%$ of White men without criminal records. Furthermore, the study found that African-American men without criminal records were less likely to receive consideration than White men with criminal records. Only $14 \%$ of African-American men without criminal records received callbacks compared to $17 \%$ of White men with criminal records.

Third, disparities in incarceration are another important discrimination-related issue faced by African-American men and boys. (For a detailed discussion on incarceration, see below).

Concurrently, there is now a significant literature suggesting that racial discrimination leads to adverse health outcomes [3034]. Geronimus et al. [35] note that the stress inherent in living in a race-conscious society that stigmatizes and disadvantages African Americans may result in disproportionate physiological deterioration, morbidity, and mortality among African Americans. This suggests that racial discrimination is a significant social determinant of health among AfricanAmerican men.

\section{Incarceration}

Incarceration is a significant aspect of life for many African-American men. First, discrimi- 
nation and reduced access to socioeconomic opportunities such as education and employment can leave African-American men with few positive life options. For example, as mentioned previously, there are disproportionate levels of expulsion and suspension among African-American boys when compared to other racial, ethnic, and gender groups in the US [36]. A direct link between these exclusionary discipline practices in schools and incarceration has been documented and described as the 'school-to-prison pipeline' [37].

Second, due to biases in police and prosecutor discretion, and sentencing guidelines, incarceration impacts disproportionate numbers of African-American men. African-American men are arrested, convicted, and incarcerated at higher rates than other racial and ethnic groups [38]. At midyear 2007, Black men were 6 times more likely to be held in custody than White males. In addition, the incarceration rate for Black men was 4,618 per 100,000 compared with 1,747 per 100,000 for Hispanic men and 773 per 100,000 for White men [39].

At the same time, there is evidence to suggest a connection between incarceration and health status $[40,41]$. As noted earlier, it has been suggested that stress can lead to poor health outcomes [22]. Thus, if we consider that prisons are high stress environments, it follows that they are likely to have a negative impact on health [40]. Additionally, the stressors associated with life after release (e.g. unemployment, inadequate access to housing and health services) may have a negative impact on the health of African-American men [40]. In short, incarceration and its related stressors are other significant social determinants of health among this population.

\section{Social determinants of health behavior}

As noted previously, research and programs relating to African-American men's health often focus on health behavior [2]. This may be due to the fact that men in general have significantly less healthy lifestyles than women. Males of all ages are more likely than females to engage in behaviors that increase the risk of disease, injury, and death, including the use/ overuse of tobacco, alcohol, other drugs, as well as high risk sexual activity and violence [42].
However, we argue in this review that explaining unhealthy behaviors simply as a matter of individual choice may be counterproductive since it leads towards a "blaming the victim approach' whereby disadvantaged populations are blamed for using unhealthy coping mechanisms for dealing with their difficult social circumstances [43]. Additionally, an emphasis solely on individual choice fails to address underlying issues of why disadvantaged people adopt these behaviors [43].

As discussed in the previous section, AfricanAmerican men are exposed to a whole host of social and environmental conditions that can have a negative impact on their health status. In addition, we consider that these difficult social and environmental conditions can also have a negative impact on health behavior. Indeed the social environment can encourage the practice of unhealthy behavior and discourage the practice of healthy behavior in a number of ways [44]. In relation to African-American men, unhealthy products such as alcohol are often disproportionately marketed in the Black community. LaVeist \& Wallace [45] found that liquor stores are disproportionately located in predominantly Black census tracts, even after controlling for census tract SES. Their study also demonstrated significant correlations between the location of liquor stores and the risk of health-related social problems in low-income neighborhoods.

Additionally, as indicated earlier, unfavorable social and economic conditions such as those faced by many African-American men can create psychosocial stress. This, in turn, can have a negative effect on health behavior [17]. As indicated by a national survey [46], Americans engage in unhealthy behaviors such as comfort eating and smoking to help cope with stress.

Moreover, as noted in the previous section, above, due to disproportionately low incomes when compared with other Americans, African-American men are often located in unfavorable neighborhood locations. A lack of recreational facilities and worry about personal safety in these locations can discourage leisure time and physical exercise [44]. The social environment can also lead to reduced access to goods and services that are necessary to maintain health. Many businesses avoid segregated urban areas, which frequently results in fewer, poorer quality and often more expensive goods and 
services than those available in less segregated areas. This in turn can lead to poorer nutrition [44].

In short, African-American men are exposed to a whole host of social and environmental conditions that can have a negative impact on health behavior as well as health status.

\section{Social determinants of health care}

In addition to the aforementioned social determinants of health, health care has also recently started to be considered as a social determinant of health. Indeed, the barriers faced by certain population groups at the point of care play a key role in the poor health of these populations [47]. With respect to men generally, gender stereotypes and assumptions can affect the quality of men's health care. For example, physicians may make the assumption that men are not interested in seeking psychosocial support for health problems [48].

African-American men, in particular, face reduced access to quality health care. Commentators have speculated that the reasons for the lower quality in health services provided to African-American men may be due to a lack of cultural competency and a lack of diversity in the health care workforce $[2,18,49]$. Health care providers who are unfamiliar with diverse populations may unintentionally be influenced by negative stereotypes of men of color [49].

In 2003, the groundbreaking Institute of Medicine report, Unequal Treatment [4] found that African Americans (and Hispanics) tend to receive a lower quality of health care than Whites across a range of disease areas (including cancer, cardiovascular disease, HIV/AIDS, diabetes, mental health, and other chronic and infectious diseases). Additionally, the Institute of Medicine found that African Americans are more likely than Whites to receive less desirable services, such as amputation of all or part of a limb. They also showed that disparities are found even when clinical factors, such as the stage of disease presentation, age, and severity of disease are taken into account. In addition, the report documented disparities across a range of clinical settings, including public and private hospitals, teaching and non-teaching hospitals. Furthermore, it was shown that disparities in care are associated with higher mortality among minorities who do not receive the same services as Whites (e.g. surgical treatment for small-cell lung cancer). With specific reference to African-American men, Felix-Aaron et al. [50] found that there were significant differences in end-stage renal disease care that African-American and White men received, with African-American men consistently receiving worse care. Additionally, in a study exploring prostate cancer screening behaviors among Black men, Woods et al. [51] found that $62.8 \%$ of African-American men felt they were treated poorly because of their race, and $58.6 \%$ reported that their race/ethnicity influenced the quality of care they received.

With regard to quality of mental health care, there are significant inequalities between the quality of mental health services provided to African Americans and the quality of services provided to Whites [52]. For example, research indicates that there is disproportionate prescribing of older and/or less utilized antidepressant medications to African Americans; the newer antidepressant medications that have fewer side effects are prescribed less often to African Americans than to Whites [53]. In addition, research also suggests that African Americans are over diagnosed with psychotic disorders such as schizophrenia. Even when compared with Whites who display the same symptoms, African Americans are more likely to be diagnosed with schizophrenia, and less likely to be diagnosed with affective disorders such as depression [54].

The above examples demonstrate that quality of health care is a crucial social determinant of health among African-American men.

\section{The need to apply the social determinants of health model to the health of African-American men}

Funding bodies, researchers, program developers, and policy makers must recognize the social determinants of health inequities among African-American men, including the social determinants of health status, the social determinants of health behavior, and the social determinants of health care. Health disparities research, programs, and policies for AfricanAmerican men must establish a realistic balance between researching health behavior/promoting behavior change and significantly 
addressing the social and environmental factors that interact with health behavior [2]. The following recommendations are not meant to be exhaustive, but rather illustrative of key issues that funding bodies, researchers, program developers, and policy makers should be concerned about when considering the health of African-American men.

\section{Research and programs}

Funding bodies must show a greater willingness to fund research and programs that address the social determinants of health among African-American men, including the social determinants of health status, social determinants of health behavior, and social determinants of health care. It is imperative that researchers and program developers acknowledge the necessity of moving beyond a simple health behavior model to explore the social determinants of health behavior among African-American men. In short, there is a need for more research that demonstrates that health outcomes among African-American men are related to social and economic conditions, as well as interventions which address these conditions. Additionally, more diversity may be needed among health policy researchers and program developers in order to achieve a broader research and intervention agenda [55].

\section{Social policy}

Given the impact of the social environment on the health of African-American men, policy makers must promote social policies which address these social and environmental issues. Social policies should include:

- Labor: It is necessary to strengthen systems to remove barriers to equal opportunity and adopt compensatory programs as and when necessary in employment (e.g. strengthening anti-discrimination legislation in the area of employment in relation to hiring and promotion) [56].

- Education: There is a need to strengthen systems to remove barriers to equal opportunity and adopt compensatory programs as and when necessary in education [56]. This should include reforming the system of allocating funds to schools to address the disparities in fund allocation, promoting cultural competency within the education system (e.g. educational advocacy initiatives for AfricanAmerican male students, increasing the numbers of African-American male teachers) [57], and increasing the accountability of school educators with regard to exclusionary discipline practices in schools.

- Poverty and the urban environment: It is important for policy makers to strengthen systems that act as a safety-net for low income workers and individuals who are confronted with financial hardship (e.g. increasing the minimum wage, extending unemployment benefits). In addition, it is necessary to invest in revitalizing poor neighborhoods (e.g. developing walkable communities, mixed-income housing developments, crime-prevention programs) [17].

- Criminal justice: It is imperative to establish systems to tackle racial biases in the criminal justice system including biases in police and prosecutor discretion, and sentencing guidelines. In addition, it is necessary to address the various social barriers that ex-offenders face after they are released from prison (e.g. providing incentives to employers to encourage the hiring of ex-offenders) [17].

\section{Health policy}

As argued earlier, health care is another social determinant of health. The following are examples of health policies that policy makers need to develop to address disparities in health care quality among African-American men.

- Gender-specific health services: There is a need to promote gender-specific health care within health services [58]. For example, health service providers should receive training in gender-specific health care in order that more appropriate services for men can be provided. This would include directing health care providers away from stereotypes that disadvantage men (e.g. "men are better at coping with pain") [58]. In addition, training should include communication, relationship building, patient education, and consideration for patient privacy and modesty, especially in relation to sensitive exams and cancer screening [59]. Moreover, health providers' offices should be tailored to the needs of men (e.g. services available outside working hours, availability of men's magazines in waiting rooms) [58]. 
- Culturally competent health services: It is necessary to promote the provision of culturally competent health services to AfricanAmerican men and other vulnerable minority populations. For example, health service providers should receive training in cultural competence in order that more appropriate services for this population can be provided. This would include developing an awareness of any biases relating to African-American men in order to improve service delivery [60]. This would also involve directing health care providers away from stereotypes that have a negative impact on health services (e.g. "African Americans are not likely to adhere to medical advice") [61].

- Diverse health care workforce: It is imperative that the representation of AfricanAmerican men be increased at all levels of the health care delivery system. Having health care providers who can relate to the experiences of African-American men will improve the likelihood that they will be comfortable in utilizing health services [49]. In keeping with the recommendations of the Institute of Medicine [62], health education institutions should include an applicant's race, ethnicity, and language skills in admission decisions, and have minorities represented on admission committees. In addition, Congress should increase funding for programs to increase diversity in the health care workforce.

\section{Conclusion}

It is clear that there are significant health disparities among African-American men when compared to the rest of the US population. We have argued that these disparities can often be attributed to the myriad of social and environmental factors that affect this population as well as to reduced access to quality health care. Indeed, one would be hard pressed to find a population group that better illustrates the social determinants of health. Funding bodies, researchers, program developers, and policy makers must adopt a broader framework for understanding and tackling health disparities [2]; they must address the underlying social determinants of health among African-American men.

\section{References}

[1] Mullins D, Blatt L, Gbarayor C, Yang K, Baquet $C$. Health disparities: a barrier to high-quality care. Am J Health Syst Pharmacol 2005;62:1873-82.

[2] Gadson G. The third world health status of Black American males. J Natl Med Assoc 2006;98(4):488-91.

[3] Gehlert S, Sohmer D, Sacks T, Mininger C, McClintock M, Olopade O. Targeting health disparities: a model linking upstream determinants to downstream interventions. Health Aff 2008;27(2):339-49.

[4] Smedley BD, Stith AY, Nelson AR, editors. Unequal Treatment: Confronting Racial and Ethnic Disparities in Health Care. Institute of Medicine publication. Washington, DC: National Academies Press; 2003.

[5] National Center for Health Statistics. Health, United States, 2007, with Chartbook on Trends in the Health of Americans. Hyattsville, MD: National Center for Health Statistics; 2007. Available at: http://www. cdc.gov/nchs/data/hus/hus07.pdf [Accessed November 12, 2008].

[6] The Henry J. Kaiser Family Foundation. Fact Sheet. The Health Status of African Amer- ican Men in the United States. Washington, DC: Kaiser Family Foundation; 2007. Available at: http://www.kff.org/minorityhealth/ upload/7630.pdf [Accessed November 15, 2008].

[7] Douglas JG. Clinical guidelines for the treatment of hypertension in African Americans. Am J Cardiovasc Drugs 2005;5(1):1-6.

[8] USRDS. United States Renal Data System. Bethesda, MD: National Institutes of Health, National Institute of Diabetes and Digestive and Kidney Diseases; 2005. Available at: http://www.usrds.org/.

[9] The Office of Minority Health. Stroke and African Americans. Rockville, MD: U.S. Department of Health \& Human Services, Office of Minority Health; 2008. Available at: http://www.omhrc.gov/templates/ content. aspx? $|v|=2 \&|v||D=51 \&| D=3022$ [Accessed May 5, 2009].

[10] The Office of Minority Health. African American Profile. Rockville, MD: U.S. Department of Health \& Human Services, Office of Minority Health; 2008. Available at: http:// www.omhrc.gov/templates/browse.aspx?|v| $=2 \&|v| I D=51$ [Accessed December 5, 2008].
[11] Zerhouni E. Prostate Cancer Research Plan FY 2003-FY 2008, Bethesda, MD: NIH; 2002 Available at: http://planning.cancer.gov/ pdfprgreports/prostateplan.pdf [Accessed January 4, 2010].

[12] American Lung Association. State of Lung Disease in Diverse Communities: 2007. New York, NY: American Lung Association 2007. http://www.lungusa.org/assets/documents/ publications/lung-disease-data/ SOLDDC_2007.pdf [Accessed January 4, 2010].

[13] NIDCR. Oral Cancer: What African American Men Need to Know. Bethesda, MD: National Institute of Dental and Craniofacial Research. Available at: http://www.nidcr.nih.gov/Oral Health/Topics/OralCancer/AfricanAmerican Men.htm [Accessed May 5, 2009].

[14] NIDCR. Oral Cancer Statistics. Bethesda, MD: National Institute of Dental and Caraniofacial Reseasrch. Available at: http:// www.nidcr.nih.gov/OralHealth/Topics/Oral Cancer/OralCancerStatistics.htm [Accessed May 5, 2009].

[15] The Henry J. Kaiser Family Foundation. Fact Sheet: Young African American Men in the 
United States. Washington, DC: Kaiser Family Foundation; 2006. Available at: http://www.kff.org/minorityhealth/upload/ 7541.pdf [Accessed November, 12, 2008].

[16] National Urban League. State of Black America: Portrait of the Black Male. Silver Spring, MD: Beckham Publications Group; 2007.

[17] Xanthos C. Feeling the Strain: The Impact of Stress on the Health of African-American Men. Atlanta, GA: Community Voices, Morehouse School of Medicine; 2009.

[18] Xanthos C. The Secret Epidemic: Exploring the Mental Health Crisis Affecting Adolescent African-American Males. Atlanta, GA: Community Voices, Morehouse School of Medicine; 2008.

[19] Adler NE, Snibbe AC. The role of psychosocial processes in explaining the gradient between socioeconomic status and health. Curr Dir Psychol Sci 2003;12(4):119-23.

[20] Bullard RD. Dumping in Dixie: Race, Class and Environmental Quality. Boulder, CO: Westview Press; 1990.

[21] Marmot MG, Shipley MJ. Do socioeconomic differences in mortality persist after retirement? 25-year follow up of civil servants from the first Whitehall study BMJ 1996;313:1177-80.

[22] Baum A, Garofalo JP, Yali AM. Socioeconomic status and chronic stress: does stress account for SES effects on health? Ann N Y Acad Sci 1999;896:131-44.

[23] Williams DR. Race, SES, and health: the added effects of racism and discrimination. Ann N Y Acad Sci 1999;896:173-88.

[24] Schott Foundation. Given Half a Chance: The Schott 50 State Report on Public Education and Black Males. Cambridge, MA: The Schott Foundation for Public Education; 2006.

[25] Monroe CR. Why are "bad boys" always Black? Causes of disproportionality in school discipline and recommendations for change Clearing House 2005;79(1):45-50.

[26] Salend SJ, Duhaney LM, Montgomery W. A comprehensive approach to identifying and addressing issues of disproportionate representation. Rem Spec Educ 2002;23:289-99.

[27] Roderick M. What's happening to the boys? Early high school experiences and school outcomes among African American male adolescents in Chicago. Urban Educ 2003;38:538-607.

[28] US Department of Education. Findings from the Condition of Education 1994: No 2: The Educational Progress of Black Students. Washington, DC: National Center for Educational Statistics, Office of Educational Research and Improvement; 1995.

[29] Pager D. The mark of a criminal record. Am J Sociol 2003;108(5):937-75.

[30] Krieger N, Sidney S. Racial discrimination and blood pressure: the CARDIA Study of young black and white adults. Am J Public Health 1996;86(10):1370-8.

[31] Jackson J, Brown T, Williams D, Torres $M$, Sellers SL, Brown K. Racism and the physical and mental health of African Americans: a thirteen year national panel study. Ethn Dis 1996;6(1-2):132-47.

[32] Read JG, Emerson MO. Racial context. Black immigration and the U.S. Black/White health disparity. Soc Forces 2005;84:18199.

[33] Taylor TR, Williams CD, Makambi KH, Mouton C, Harrell JP, Cozier $Y$, et al. Racial discrimination and breast cancer incidence in U.S. Black women: the Black women's health study. Am J Epidemiol 2007;166:4654.

[34] Williams DR, Yu Y, Jackson J, Anderson N. Racial differences in physical and mental health: socioeconomic status, stress, and discrimination. J Health Psychol 1997;2(3): 335-51.

[35] Geronimus AT, Hicken M, Keene D, Bound J. 'Weathering' and age patterns of allostatic load scores among blacks and whites in the United States. Am J Public Health 2006; 96(5):826-33.

[36] National Center for Education Statistics. Status and Trends in the Education of American Indians and Alaska Natives. Washington, DC: National Center for Education Statistics; 2005. Available at: http://nces.ed.gov/ pubs2005/nativetrends/ind_3_2.asp

[Accessed November 13, 2009].

[37] Fenning P, Rose J. Overrepresentation of African American students in exclusionary discipline: the role of school policy. Urban Educ 2007;42(6):536

[38] Williams N. Where are the Men?: The Impact of Incarceration and Reentry on African American Men and their Children and Families. Atlanta, GA: Community Voices, Morehouse School of Medicine; 2006.

[39] Sabol WJ, Couture H. Prison Inmates at Midyear 2007. NCJ 221944. Washington, DC: Bureau of Justice Statistics; 2008. Available at: http://bjs.ojp.usdoj.gov/content/ pub/pdf/pim07.pdf usdoj.gov/bjs/pub/pdf/ pim07.pdf [Accessed December 19, 2009].

[40] Massoglia M. Incarceration as exposure: the prison, infectious disease, and other stressrelated illnesses. J Health Soc Behav 2008;49(1):56-71.

[41] Graham L, Treadwell H, Braithwaite K. Social policy, imperiled communities and HIV/AIDS transmission in prisons: a call for zero tolerance. jmh 2008;5(4):267-73.

[42] Courtenay WH. Behavioral factors associated with disease, injury, and death among men: evidence and implications for prevention. J Mens Stud 2000;9:81142.

[43] Raphael D, Anstice S, Raine K, McGannon KR, Rizvi SK, Yu V. The social determinants of the incidence and management of type 2 diabetes mellitus: are we prepared to rethink our questions and redirect our research activities? Leadership Health Serv 2003;16:10-20.

[44] Williams DR, Collins C. Racial residential segregation: a fundamental cause of racial disparities in health. Public Health Rep 2001;116(5):404-16.

[45] LaVeist T, Wallace W. Health risk and inequitable distribution of liquor stores in African American neighborhood. Soc Sci Med 2000;51(4):613-7.

[46] APA Online. Americans Engage in Unhealthy Behaviors to Manage Stress. Washington, DC: APA; 2006. Available at: http://www.apa.org/news/press/releases/ 2006/01/stress-management.aspx. [Accessed January 4, 2010].

[47] McGibbon E, Etowa J, McPherson C. Health care access as a social determinant of health. Can Nurse 2008;104(7):22-7.

[48] Bird CE, Rieker PP. Gender matters: an integrated model for understanding men's and women's health. Soc Sci Med 1999;48(6): 745-55.

[49] Satcher D. Overlooked and underserved: improving the health of men of color. Am J Public Health 2003;93(5):707-9.

[50] Felix-Aaron K, Moy E, Kang M, Patel M, Chesley F, Clancy C. Variation in quality of care received by American men. Abstr Academy Health Meet 2004; 21: abstract no. 1228.

[51] Woods DV, Montgomery SB, Belliard JC, Ramirez-Johnson J, Wilson CM. Culture, black men, and prostate cancer: what is reality? Cancer Cont 2004;11(6): 388-96.

[52] Braithwaite Holden K, Xanthos C. Disadvantages in mental health care among African Americans. J Health Care Poor Underserved 2009;20(2A):17-23.

[53] Melfi CA, Croghan TW, Hanna MP, Robinson RL. Racial variation in antidepressant treatment in a Medicaid population. J Clin Psychiatry 2000;61(1):16-21.

[54] Baker FM, Bell CC. Issues in the psychiatric treatment of African Americans. Psychiatr Serv 1999;50(3):362-8.

[55] Treadwell HM, Ro M. Poverty, race, and the invisible men. Am J Public Health 2003; 93(5):705-7.

[56] Danziger S, Reed D, Brown T. Poverty and Prosperity: Prospects for Reducing Racial/Ethnic Economic Disparities in the United States. Geneva: UNRISD; 2004. Available at: http:// www.unrisd.org/80256B3C005BCCF9/(http AuxPages)/ED2687548CA0C7C380256B6 D0057867E/\$file/danziger.pdf. [Accessed June 29, 2008].

[57] Courtland L. Empowering young black males. ERIC Digest 1991. ERIC Document Reproduction Service No. ED341887. 
[58] Banks I. New models for providing men with health care. jmhg 2004;1:155-8.

[59] Dubé C, Fuller BK, Rosen RK, Fagan M, O'Donnell J. Men's experiences of physical exams and cancer screening tests: a qualitative study. Prev Med 2005;40:62835.
[60] Cardarelli R, Chiapa AL. Educating primary care clinicians about health disparities. Osteopath Med Prim Care 2007;1:5.

[61] Van Ryn M, Burke J. The effect of patient race and socio-economic status on physicians' perceptions of patients. Soc Sci Med 2000;50(6):813-28.
[62] Smedley BD, Butler AS, Bristow LR, editors. In the Nation's Compelling Interest: Ensuring Diversity in the Health Care Workforce. Institute of Medicine publication. Washington, DC: National Academies Press; 2004. 